\title{
Critical Parameters in the Isolation of Mitochondria from Candida utilis Grown in Continuous Culture
}

\author{
By PETER M. BRUINENBERG, JOHANNES P. VAN DIJKEN, \\ J. GIJS KUENEN AND W. ALEXANDER SCHEFFERS* \\ Laboratory of Microbiology, Delft University of Technology, Julianalaan 67A, 2628 BC Delft, \\ The Netherlands
}

(Received 5 November 1984)

\begin{abstract}
The successive steps in the isolation of mitochondria from chemostat-grown Candida utilis have systematically been investigated for their effects on organelle integrity. Growth rate had a profound effect on the susceptibility of carbon-limited cells towards Zymolyase, whereas the nature of the carbon source had no effect. Stabilization of spheroplasts with at least $2 \mathrm{M}$-sorbitol was required to prevent premature lysis. This was concluded from the amounts of glucose-6phosphate dehydrogenase liberated during Zymolyase treatments. The influence of the method for disruption of spheroplasts on the quality of the mitochondria was analysed with particular emphasis on respiratory control values and the distribution of marker enzymes among the cell fractions. Disruption by osmotic shock resulted in mitochondria without respiratory control and a high degree of solubilization of NADH and NADPH dehydrogenase activities. Only a gradual decrease of the osmotic value of the medium, preferably by dialysis against a hypotonic buffer, in combination with mechanical disruption with a Potter-Elvehjem homogenizer yielded mitochondria with high respiratory control values and a high retention of NADH dehydrogenase in the organelle. It is concluded that, for the quality of mitochondrial preparations from yeasts, the distribution of NADH dehydrogenase among the cell fractions is a more reliable measure than that of the usual marker enzymes.
\end{abstract}

\section{INTRODUCTION}

Although the use of chemostat cultivation for studies on microbial physiology is well established, this technique has seldom been used for investigating the properties of mitochondria of micro-organisms in relation to environmental parameters. A few studies have appeared on the effects on mitochondria of the mineral composition of media for chemostatgrown Candida utilis (Light \& Garland, 1971; Aiking et al., 1977) but information on mitochondrial properties of chemostat-grown yeasts in relation to carbon and nitrogen metabolism is limited.

Both dissimilatory and assimilatory routes have an important bearing on the fluxes of redox equivalents in the yeast cell (Bruinenberg et al., 1983a,b). In order to quantify the role of mitochondrial redox metabolism attempts were made to establish the oxidative properties of mitochondria of chemostat-grown $C$. utilis as a function of the carbon and nitrogen sources supplied for growth. During these studies it was noticed that the various published procedures for the isolation of mitochondria from yeasts had several shortcomings.

This paper reports the influence of various steps in the isolation procedure on the integrity of mitochondria from chemostat-grown $C$. utilis as estimated by respiratory control values and the distribution of marker enzymes. Particular attention was paid to the distribution of NADH and NADPH dehydrogenases since it appeared that the distribution of these activities, rather than that of classical marker enzymes such as cytochrome $c$ oxidase, is of crucial importance in establishing the functional integrity of mitochondria. 


\section{METHODS}

Micro-organism and growth conditions. Candida utilis CBS 621 was maintained on malt agar slopes. The organism was grown at $30^{\circ} \mathrm{C}$ and $\mathrm{pH} 5 \cdot 0$ in a laboratory fermenter with a 1 litre working volume of the type described by Harder et al. (1974). The dissolved oxygen tension was recorded with a steam-sterilizable Clark-type oxygen electrode and was kept constant at $40 \%$ of air saturation by automatic adjustment of the stirrer speed. The $\mathrm{pH}$ was controlled by automatic addition of $1 \mathrm{M}-\mathrm{NaOH}$ or $0.5 \mathrm{M}-\mathrm{H}_{2} \mathrm{SO}_{4}$. The medium was prepared according to Bruinenberg et al. (1983b). Unless mentioned otherwise, the organism was grown under glucose limitation with ammonium as the nitrogen source, at a dilution rate of $0 \cdot 1 \mathrm{~h}^{-1}$.

Buffers. In all isolation procedures buffer A ( $25 \mathrm{~mm}$-potassium phosphate buffer $\mathrm{pH} 7.5$ containing $1 \mathrm{mM}$-EDTA and $1 \mathrm{~mm}-\mathrm{MgCl}_{2}$ ) was used.

Estimation of spheroplast formation. The degree of spheroplast formation was determined by measuring sensitivity to an osmotic shock. This was done by following the optical density at $660 \mathrm{~nm}$ of the incubation mixture with a Vitatron Universal Photometer (Vitatron Scientific Instruments, Dieren, The Netherlands), after diluting samples 200-fold with water at fixed time intervals during the Zymolyase treatment. The proportion of osmotically insensitive cells in the suspension is expressed as the percentage of the optical density at a certain time relative to the value at zero time, just after the addition of Zymolyase.

Determination of the critical sorbitol concentration during Zymolyase treatment. Samples from steady-state cultures $\left(0.5 \mathrm{~g}\right.$ cell dry weight) were harvested by centrifugation at $0{ }^{\circ} \mathrm{C}$ (GSA rotor; Sorvall RC-5B centrifuge) at 5000 r.p.m. for $10 \mathrm{~min}$. Cells were washed twice with $20 \mathrm{ml}$ ice-cold buffer A to which different amounts of sorbitol were added to obtain the desired osmotic value. Cells were then collected by centrifugation in an SS-34 rotor for $10 \mathrm{~min}$ at 10000 r.p.m. and $0{ }^{\circ} \mathrm{C}$ and resuspended in $5 \mathrm{ml}$ buffer $\mathrm{A}$ of the appropriate osmotic value. The suspension was brought to $37^{\circ} \mathrm{C}$ and $4 \mathrm{mg}$ Zymolyase-5000 was added. At intervals, samples were withdrawn to determine the degree of spheroplast formation. In addition, the proportion of lysed spheroplasts in the incubation mixture was determined by measuring the activity of glucose-6-phosphate dehydrogenase after centrifugation of the sample in the Eppendorf centrifuge. Total activity of the glucose-6-phosphate dehydrogenase in the suspension was determined after sonication of a sample that had been incubated with Zymolyase for $1 \mathrm{~h}$ at $37^{\circ} \mathrm{C}$ for $2 \mathrm{~min}$ at $4{ }^{\circ} \mathrm{C}$ with an MSE-150W sonicater. Unbroken cells and debris were removed by centrifugation and the activity of glucose-6-phosphate dehydrogenase in the supernatant was regarded as corresponding to $100 \%$ lysis.

Preparation of spheroplasts for isolation of mitochondria. Samples from steady-state cultures ( $2 \mathrm{~g}$ cell dry weight) were harvested as described above. Throughout the isolation procedure the SS-34 rotor of the Sorvall RC-5B centrifuge was used. Cells were washed twice with $20 \mathrm{ml}$ ice-cold buffer A containing $2 \mathrm{M}$-sorbitol and collected by centrifugation at $0^{\circ} \mathrm{C}$ for $10 \mathrm{~min}$ at 10000 r.p.m. Cells were then resuspended in $10 \mathrm{ml} 2 \mathrm{M}$-sorbitol in buffer $\mathrm{A}$, heated to $37^{\circ} \mathrm{C}$ and mixed with $10 \mathrm{ml}$ of the same buffer at $37^{\circ} \mathrm{C}$ to which Zymolyase had been added to the desired concentration. In all experiments Zymolyase-5000 was used except for the experiments at $D=0.05 \mathrm{~h}^{-1}$ in which Zymolyase- 60000 was used. After $1 \mathrm{~h}$ at $37^{\circ} \mathrm{C}$ the incubation was stopped by cooling on ice. The degree of spheroplast formation, determined as described above, was always more than $85 \%$. Spheroplasts were harvested by centrifugation at 6000 r.p.m. for $10 \mathrm{~min}$ and washed twice with $20 \mathrm{ml}$ ice-cold $2 \mathrm{M}$-sorbitol in buffer $\mathrm{A}$.

Disruption of spheroplasts. Spheroplasts were disrupted by one of four methods:

(I) Spheroplasts from a suspension in $2 \mathrm{M}$-sorbitol in buffer $\mathrm{A}$ were pelleted at $6000 \mathrm{r} . \mathrm{p} . \mathrm{m}$. for $10 \mathrm{~min}$ and osmotically shocked by rapid mixing with $0.25 \mathrm{M}$-sorbitol in buffer $\mathrm{A}$. The final concentration of sorbitol as determined with a diffractometer was $0.75 \mathrm{M}$. After the suspension had been homogenized with one stroke of a Potter-Elvehjem homogenizer, mitochondria were isolated. The homogenizer used in this and the following methods had a clearance of $28 \mu \mathrm{m}$.

(II) Mild osmotic lysis was obtained by slowly diluting a suspension of spheroplasts in $2 \mathrm{M}$-sorbitol, by adding dropwise, under magnetic stirring, $0.5 \mathrm{M}$-sorbitol in buffer $\mathrm{A}$ to a final concentration of $0.65 \mathrm{M}$-sorbitol. Again, after one stroke in a Potter-Elvehjem homogenizer, mitochondria were isolated.

(III) The osmotic value of the suspension was decreased to $0.65 \mathrm{M}$-sorbitol by five successive washing steps with buffer A containing decreasing amounts of sorbitol. Supernatants of washings were discarded. Finally, spheroplasts were suspended in $20 \mathrm{ml}$ buffer A containing $0.65 \mathrm{M}$-sorbitol. Disruption of spheroplasts was achieved by 10 strokes in a Potter-Elvehjem homogenizer at 100 r.p.m.

(IV) The concentration of $2 \mathrm{M}$-sorbitol was decreased to $0.65 \mathrm{M}$-sorbitol by dialysis of the suspension at room temperature against 41 buffer $A$ without sorbitol. Depending on the exact temperature, 100-120 min were required to reach the desired concentration of sorbitol in the dialysis bag as determined with a refractometer. Spheroplasts were collected as described above and resuspended in $20 \mathrm{ml} 0.65 \mathrm{M}$-sorbitol in buffer A. Spheroplasts were disrupted by 10 strokes at 100 r.p.m. in a Potter-Elvehjem homogenizer.

Fractionation of cell homogenates. The suspension of disrupted spheroplasts was centrifuged until whole cells, unbroken spheroplasts, and heavy cell parts such as nuclei had been removed, as judged by light microscopy. Usually two centrifugations of $15 \mathrm{~min}$ at 4000 r.p.m. were sufficient. The final supernatant is referred to as the total fraction $(T)$. From this fraction, particulate fractions $\left(P_{1}\right.$ and $\left.P_{2}\right)$ were obtained after centrifugation at 
10000 r.p.m. for $10 \mathrm{~min}$ and at 20000 r.p.m. for $20 \mathrm{~min}$, respectively. The clear supernatant obtained after the second centrifugation is referred to as the soluble fraction (S). Centrifugation of this fraction for $4 \mathrm{~h}$ at $150000 \mathrm{~g}$ did not result in further sedimentation of particles. Both fractions $P_{1}$ and $P_{2}$ were washed once with $0.65 \mathrm{M}$-sorbitol in buffer $A$, containing $1 \mathrm{mg}$ bovine serum albumin $\mathrm{ml}^{-1}$ (BSA; fatty acid-free). The pellets of fractions $P_{1}$ and $P_{2}$ were resuspended in appropriate volumes of $0.65 \mathrm{M}$-sorbitol in buffer A containing $1 \mathrm{mg} \mathrm{BSA} \mathrm{ml}^{-1}$.

Polarographic measurements. Oxygen consumption rates were measured polarographically at $30^{\circ} \mathrm{C}$ with a Clarktype oxygen electrode. The assay mixture $(3 \mathrm{ml})$ contained $25 \mathrm{~mm}$-potassium phosphate buffer, $\mathrm{pH} 7.0,5 \mathrm{~mm}$ $\mathrm{MgCl}_{2}$ and $0.65 \mathrm{M}$-sorbitol. Reactions were started with $0.25 \mathrm{mM}-\mathrm{NADH}, 0.75 \mathrm{mM}-\mathrm{NADPH}$ or $5 \mathrm{~mm}-2-$ oxoglutarate. For measurement of 2-oxoglutarate oxidase activity, $1 \mathrm{mM}$-malate was added before the addition of 2-oxoglutarate (Schwitzguébel \& Palmer, 1982). Respiratory control values were determined according to Chance \& Williams (1956) by adding 0.083 mM-ADP.

Enzyme assays. Enzyme activities in the various fractions were determined after sonication at $4{ }^{\circ} \mathrm{C}$ for $2 \mathrm{~min}$ in an MSE-150W sonicator. Glucose-6-phosphate dehydrogenase (EC 1.1.1.49) was assayed as described earlier (Bruinenberg et al., 1983b). Cytochrome $c$ oxidase (EC 1.9.3.1) was assayed in $50 \mathrm{~mm}$-potassium phosphate buffer, $\mathrm{pH} 7 \cdot 0$, with $0.04 \mathrm{~mm}$-cytochrome $c$ (reduced). The reaction was started by the addition of enzyme and was recorded at $550 \mathrm{~nm}$. Cytochrome $c$ was reduced by titration with ascorbic acid. NADH dehydrogenase (EC 1.6.99.3) and NADPH dehydrogenase (EC 1.6.99.1) were assayed with ferricyanide as the electron acceptor. The assay mixture contained $50 \mathrm{~mm}$-potassium phosphate buffer, pH 6.0, $5 \mathrm{~mm}$-potassium cyanide, $1 \mathrm{~mm}$ potassium ferricyanide, and $0.15 \mathrm{mM}-\mathrm{NADH}$ or NADPH. The reaction was started by adding the enzyme preparation and was recorded at $340 \mathrm{~nm}$. The distribution of the above enzymes among the fractions $P_{1}, P_{2}$ and $S$ is expressed as the percentage of their respective activities in the total homogenate $(T)$.

Protein was assayed by the Lowry method with BSA as the standard.

Data reported in this paper refer to the mean of 2-5 separate isolations of mitochondria.

Electron microscopy. Particulate fractions were mixed in buffer A containing 3\%(v/v) glutaraldehyde for $1 \mathrm{~h}$ at room temperature, washed five times with $0 \cdot 1 \mathrm{M}$-cacodylate buffer, $\mathrm{pH} 7 \cdot 2$, containing $10 \mathrm{mM}-\mathrm{CaCl}_{2}$, and stained in the latter buffer with $1 \%$ osmium tetroxide and $0.05 \%$ Ruthenium red for $17 \mathrm{~h}$ at room temperature. After dehydration in a graded ethanol series, fractions were embedded in Spur. Ultra-thin sections, post-stained with uranyl acetate and lead citrate, were examined in a Philips EM 201.

Biochemicals and enzymes. Zymolyase- 5000 and Zymolyase- 60000 were from Kirin Brewery, Japan. Bovine serum albumin (fatty acid-free) and cytochrome $c$ (horse heart) were from Sigma. Other biochemicals were from Boehringer.

\section{RESULTS}

\section{Choice of cell wall-lytic enzyme and pretreatment of cells}

In preliminary experiments with various yeasts grown in chemostat culture under glucose limitation it was noticed, in agreement with published data, that the rate of spheroplast formation with Zymolyase is an order of magnitude higher than with the snail gut enzymes Helicase. It was therefore decided to use Zymolyase. With chemostat-grown cells of $C$ utilis, pretreatment of cells with reducing agents was not required for rapid spheroplast formation with Zymolyase. In the isolation procedures described below treatment of cells with mercaptoethanol or dithiothreitol was therefore omitted.

\section{Buffer system}

Tris buffers could not be used in the isolation of mitochondria from $C$. utilis since they resulted in sticky and fluffy spheroplast and mitochondria preparations. Therefore, phosphate buffers were used at $\mathrm{pH} 7.5$ (the $\mathrm{pH}$ optimum of Zymolyase is between $7 \cdot 0$ and 8.0 , as specified by the manufacturer).

It was necessary to add equimolar amounts of $\mathrm{Mg}^{2+}$, to obtain high respiratory control values, and EDTA, otherwise very sticky spheroplast and mitochondria preparations resulted, which were difficult to suspend. Sorbitol was chosen as osmotic stabilizer of the spheroplasts and mitochondria. The release of glucose-6-phosphate dehydrogenase during the enzymic degradation of the cell wall in buffers with different osmolarities of sorbitol showed that at least $2 \mathrm{M}$-sorbitol must be used (Fig. 1). In $1.5 \mathrm{M}$-sorbitol solutions $30 \%$ of the spheroplasts lysed (Fig. $1 \mathrm{~b}$ ) and lysis further increased in $1 \mathrm{M}$-sorbitol (Fig. $1 \mathrm{c}$ ). For the stabilization of spheroplasts, sorbitol could not be replaced by potassium chloride: even in $3 \mathrm{M}$-potassium chloride extensive lysis of spheroplasts was observed during the Zymolyase treatment. 

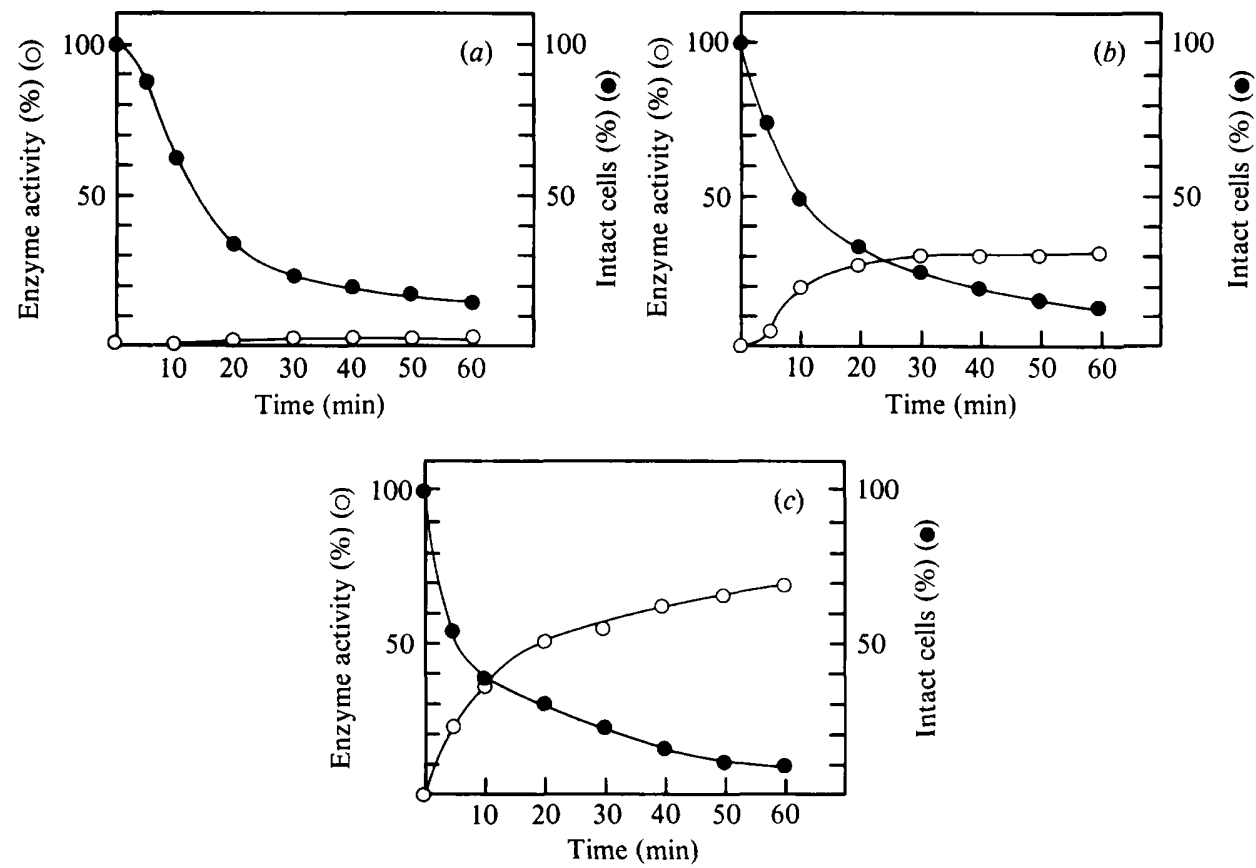

Fig. 1. Release of glucose-6-phosphate dehydrogenase activity during Zymolyase treatment of C. utilis grown in continuous culture at $D=0 \cdot 1 \mathrm{~h}^{-1}$. Sorbitol was used as stabilizer for spheroplasts at $2 \mathrm{M}(a)$, $1.5 \mathrm{M}(b)$ and $1 \mathrm{M}(\mathrm{c})$, respectively. Proportion of osmotically insensitive cells expressed as the percentage of cells present at zero time; $O$, release of glucose-6-phosphate dehydrogenase in the supernatant expressed as the percentage of the total activity.

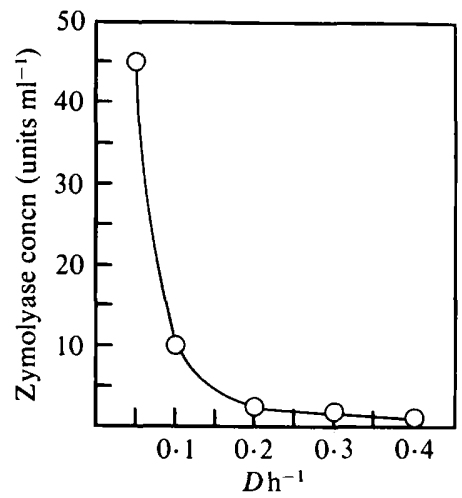

Fig. 2. Zymolyase sensitivity of cells of $C$. utilis grown in continuous culture in relation to growth rate. Values given are the amount of Zymolyase in units $\mathrm{ml}^{-1}$ required to obtain $50 \%$ spheroplast formation in $15-20 \mathrm{~min}$ at $37^{\circ} \mathrm{C}$ with a biomass concentration of $0.12 \mathrm{~g}$ dry weight $\mathrm{ml}^{-1}$.

\section{Susceptibility of cells to Zymolyase}

Zymolyase is a crude enzyme preparation and even the best quality has protease and lipase activities (specifications of the manufacturer). In order to avoid unnecessarily high concentrations of Zymolyase and to obtain the same degree of cell wall removal for all growth conditions, the minimum amount of Zymolyase required for $50 \%$ spheroplast formation within 15-20 min was determined. The susceptibility of the cells to Zymolyase was highly dependent on the growth rate of the organism (Fig. 2). Cells grown at low dilution rates required increasing amounts of Zymolyase to obtain the same rate of spheroplast formation. The sensitivity of the cell wall to Zymolyase was not influenced by the carbon source (glucose, xylose, acetate, ethanol, 
Table 1. Distribution of enzymes in particulate and soluble fractions after disruption of spheroplasts of Candida utilis by various procedures

See Methods for details of spheroplast treatments.

\begin{tabular}{|c|c|c|c|c|c|}
\hline \multirow[b]{2}{*}{ Enzyme } & \multicolumn{4}{|c|}{ Relative amount $(\%)$} & \multirow{2}{*}{$\begin{array}{c}\text { Recovery } \\
(\%)\end{array}$} \\
\hline & $\mathrm{T}$ & $P_{1}$ & $P_{2}$ & $\mathbf{S}$ & \\
\hline \multicolumn{6}{|c|}{ Method I } \\
\hline Glucose-6-phosphate dehydrogenase & 100 & 1 & 1 & 82 & 84 \\
\hline Cytochrome $c$ oxidase & 100 & 58 & 5 & 2 & 65 \\
\hline NADH dehydrogenase & 100 & 3 & 1 & 72 & 76 \\
\hline NADPH dehydrogenase & 100 & 2 & 1 & 99 & 102 \\
\hline \multicolumn{6}{|c|}{ Method II } \\
\hline Glucose-6-phosphate dehydrogenase & 100 & 1 & 2 & 95 & 98 \\
\hline Cytochrome $c$ oxidase & 100 & 64 & 5 & 2 & 71 \\
\hline NADH dehydrogenase & 100 & 31 & 4 & 64 & 99 \\
\hline NADPH dehydrogenase & 100 & 8 & 1 & 98 & 107 \\
\hline \multicolumn{6}{|c|}{ Method III } \\
\hline Glucose-6-phosphate dehydrogenase & 100 & 1 & 0 & 100 & 101 \\
\hline Cytochrome $c$ oxidase & 100 & 47 & 5 & 1 & 53 \\
\hline NADH dehydrogenase & 100 & 60 & 10 & 31 & 101 \\
\hline NADPH dehydrogenase & 100 & 25 & 3 & 69 & 97 \\
\hline \multicolumn{6}{|c|}{ Method IV } \\
\hline Glucose-6-phosphate dehydrogenase & 100 & 0 & 2 & 85 & 87 \\
\hline Cytochrome $c$ oxidase & 100 & 97 & 8 & 0 & 105 \\
\hline NADH dehydrogenase & 100 & 81 & 6 & 18 & 105 \\
\hline NADPH dehydrogenase & 100 & 34 & 4 & 46 & 84 \\
\hline
\end{tabular}

or gluconate). However, cells grown with nitrate as the nitrogen source were more sensitive to Zymolyase. As compared to ammonium, nitrate-grown cells required only half the amount of enzyme for the same rate of spheroplast formation. Although spheroplast formation was almost complete after $30 \mathrm{~min}$ (Fig. 1a), electron microscopy of the suspension showed that approximately $75 \%$ of the spheroplasts possessed a nearly complete cell wall. In view of the gentle methods required for disruption of the spheroplasts (see below), incubation with Zymolyase was extended for a further $30 \mathrm{~min}$. This resulted in virtually complete removal of the cell wall. Prolonged incubation of spheroplasts with Zymolyase resulted in extensive lysis. Incubation of cells with Zymolyase in $2 \mathrm{M}$-sorbitol for $3 \mathrm{~h}$ provoked total lysis, as judged by light microscopy, and the release of glucose-6-phosphate dehydrogenase. Fractionation of such suspensions yielded mitochondria lacking respiratory control. Apparently, uncontrolled premature lysis of spheroplasts during prolonged incubation with Zymolyase leads to damage to the mitochondria. This may be caused by liberation of digestive enzymes from lysed cells. Indeed, incubation of intact mitochondria with Zymolyase-5000 $\left(0.5 \mathrm{mg} \mathrm{ml}^{-1}\right)$ alone did not affect activity and respiratory control. Thus, the time of exposure of spheroplasts to Zymolyase is of critical importance in isolating functionally intact mitochondria.

\section{Disruption of spheroplasts and isolation of mitochondria}

Osmotic lysis is usually employed to disrupt spheroplasts. When, however, spheroplasts of $C$. utilis prepared in $2 \mathrm{M}$-sorbitol were resuspended in buffer containing $0.25 \mathrm{M}$-sorbitol (method I, see Methods) the mitochondria obtained did not exhibit respiratory control with NADH, NADPH or 2-oxoglutarate. The distribution of the enzymes glucose-6-phosphate dehydrogenase and cytochrome $c$ oxidase was nevertheless as expected (Table 1). NAD(P)H dehydrogenase activities were found almost exclusively in the soluble fraction. Also mild osmotic lysis by slow dilution of the spheroplast suspension with $0.5 \mathrm{M}$-sorbitol to a final concentration of $0.65 \mathrm{M}$ resulted in high activities of NADH and NADPH dehydrogenases in the soluble fraction (method II; Table 1). Glucose-6-phosphate dehydrogenase and cytochrome $c$ oxidase were 


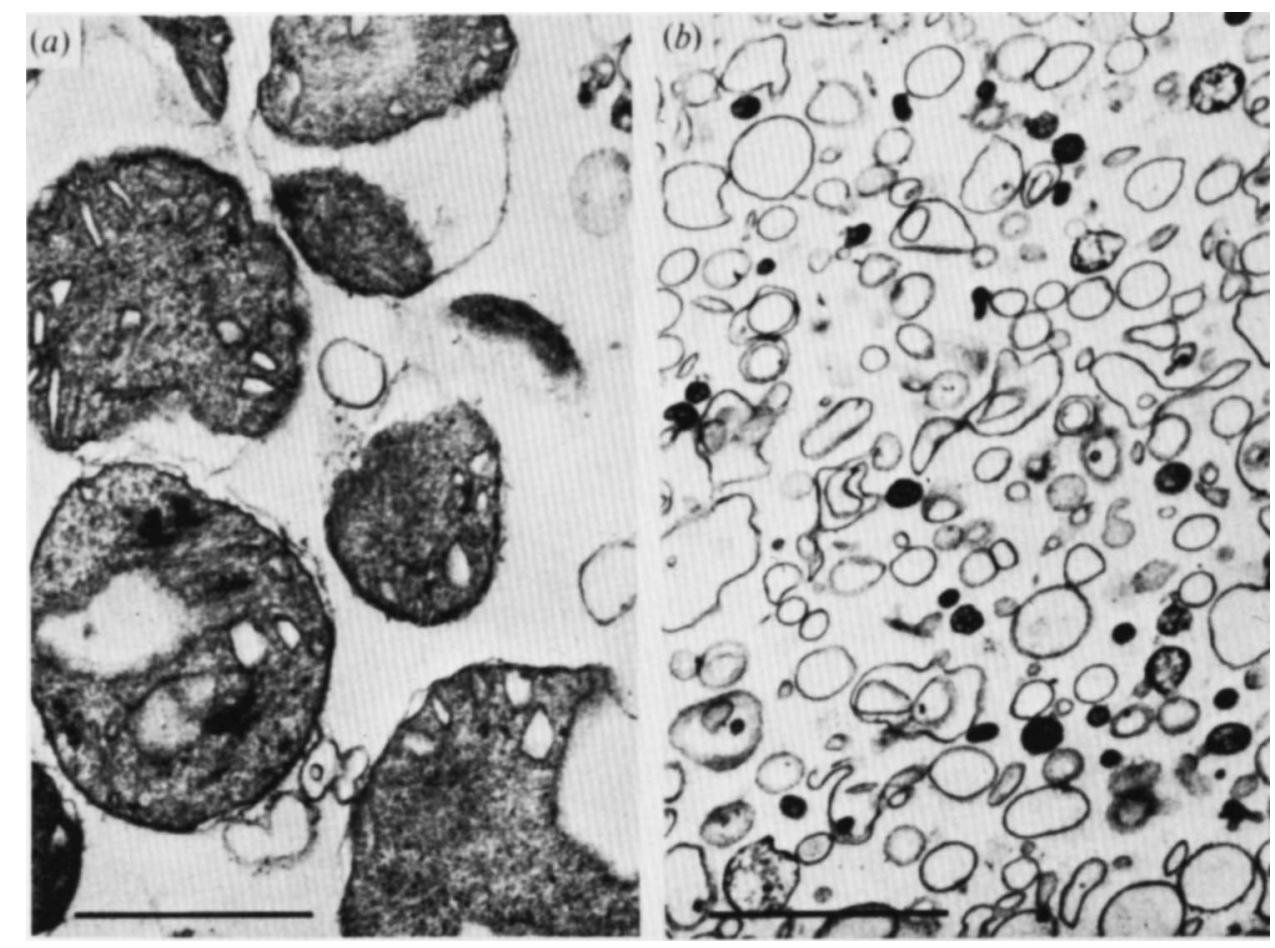

Fig. 3. Electron micrographs of the particulate fractions obtained with the dialysis procedure (method IV) showing mitochondria in fraction $P_{1}(a)$ and membrane vesicles in fraction $P_{2}(b)$. Bars, $1 \mu \mathrm{m}$.

Table 2. Summary of results obtained with various procedures for disruption of spheroplasts

$\begin{array}{lccc}\text { Mespiratory } & \begin{array}{c}\text { Percentage } \\ \text { NADH } \\ \text { control value } \\ \text { with NADH }\end{array} & \begin{array}{c}\text { Sp. act. of } \\ \text { dehydrogenase } \\ \text { in fraction } \mathbf{P}_{1}\end{array} & \begin{array}{c}\text { cytochrome } c \\ \text { oxidase } \\ \text { in fraction } \mathbf{P}_{1} \text { * }\end{array} \\ \text { Osmotic shock } & 1.0 & 3 & 430 \\ \text { Mild osmotic lysis } & 2.0 & 31 & 1120 \\ \text { Mechanical disruption after washing } & 1.8 & 60 & 1290\end{array}$

* Expressed as nmol cytochrome $c$ oxidized $\mathrm{min}^{-1}$ (mg protein $)^{-1}$. The extinction coefficient of reduced cytochrome $c$ was taken as $18.5 \mathrm{~mm}^{-1} \mathrm{~cm}^{-1}$.

recovered in the expected fractions. Mitochondria in fraction $P_{1}$ exhibited respiratory control with NADH, NADPH and 2-oxoglutarate (values of 2, 1.6, and 2, respectively) indicating that mitochondria were intact. In fraction $\mathrm{P}_{2}$ respiratory control with these substrates was always very low or absent, although oxygen consumption with NADH, NADPH and 2-oxoglutarate was detectable. A better distribution of NADH and NADPH dehydrogenase activities was obtained when the spheroplasts were lysed in $0.65 \mathrm{M}$-sorbitol and then disrupted mechanically (method III; Table 1). This yielded mitochondria with respiratory control values for NADH, NADPH and 2-oxoglutarate of $1.8,1.8$ and 2.5 , respectively. A higher yield of mitochondria could be obtained by circumventing the successive centrifugation steps of method III. This was achieved by dialysis of the spheroplast suspension against buffer A without sorbitol (method IV). This procedure also resulted in a higher recovery of NADH and NADPH dehydrogenase activities in the particulate fractions (compare methods III and IV; Table 1). The respiratory control values with NADH, NADPH and 2-oxoglutarate were similar to those obtained with 
method III (2, 1.9 and 2.5 , respectively). Further lowering of the sorbitol concentration to $0.5 \mathrm{M}$, either by consecutive washings or by dialysis, resulted in lower respiratory control values. In addition, more of the NADH and NADPH dehydrogenase activities were recovered in the soluble fraction (results not shown).

Method IV was applicable for all growth conditions tested (Bruinenberg et al., 1985), except that with spheroplasts of cells grown on acetate or ethanol as the carbon source lowering the sorbitol concentration to $0.65 \mathrm{M}$ resulted in complete lysis of spheroplasts and low respiratory control values of the mitochondria. For these carbon sources spheroplasts had to be disrupted in $1 \mathrm{M}$-sorbitol to obtain high-quality mitochondria. The yield of mitochondrial protein collected in fraction $P_{1}$ was between 12 and $16 \mathrm{mg}$ protein ( $\mathrm{g}$ dry cells) ${ }^{-1}$. A summary of the results obtained with the various procedures is presented in Table 2. From the specific activities of cytochrome $c$ oxidase it can be concluded that the dialysis procedure yields the purest preparation of mitochondria. Electron micrographs of the particulate fractions obtained with method IV are shown in Fig. 3. Whereas the $\mathrm{P}_{1}$ fraction was enriched in mitochondria (Fig. 3a), these organelles seemed largely absent in the $\mathrm{P}_{2}$ fraction which contained only membrane vesicles (Fig. $3 b$ ).

\section{DISCUSSION}

High respiratory control values of isolated mitochondria are generally taken as an indication of functional integrity of the organelle (Lloyd, 1974). According to this criterion, the best way of disrupting spheroplasts to isolate mitochondria from $C$. utilis is either mild osmotic lysis or mechanical breakage with a Potter-Elvehjem homogenizer. Invariably, the classical marker enzyme cytochrome $c$ oxidase was found almost exclusively in the mitochondrial fraction (Table 1). However, the distribution of NADH dehydrogenase activity over the fractions varied considerably with the method used for spheroplast disruption (Table 2). This may be taken as an indication of different degrees of damage to the mitochondria. On the basis of this criterion, even with the most gentle method (IV) of spheroplast disruption, some damage to the mitochondria seems inevitable, however it cannot be excluded that the cytoplasm exhibits some NADH dehydrogenase activity of its own. Taking into account both respiratory control and enzyme distribution, we conclude that mechanical disruption in a Potter-Elvehjem homogenizer is the best method for obtaining crude preparations of high-quality mitochondria. A similar observation has been made for the isolation of (osmotically very fragile) yeast peroxisomes (Zwart et al., 1983).

Even with the most gentle method of disruption of spheroplasts, the main proportion of NADPH dehydrogenase activity was found in the soluble fraction (method IV; Table 1). NADPH dehydrogenase activity is thought to be part of the microsomal cytochrome P-450 system (Horecker, 1978; Delaissé et al., 1981). It appears that, apart from alkane-grown yeasts, this system is only present in yeasts when grown under oxygen limitation (Kärenlampi et al., 1981; Trinn et al., 1982). Indeed, we have been unable to detect cytochrome P-450 in whole cells and cell homogenates of $C$. utilis grown in aerobic, glucose-limited chemostat cultures (P. M. Bruinenberg, unpublished). Although not as pronounced as for the NADH dehydrogenase, more of the NADPH dehydrogenase activity is found in the particulate fractions when gentle methods of disruption are used. This observation suggests that in C. utilis at least part of the NADPH dehydrogenase is mitochondrial. Furthermore, the enzyme may be functionally coupled to the respiratory chain, as evidenced by the stimulation of NADPH oxidation after the addition of ADP. This is in line with the observation (P. M. Bruinenberg, unpublished) that during sucrose gradient centrifugation of $P_{1}$ fractions NADPH dehydrogenase cosediments with NADH dehydrogenase and cytochrome $c$ oxidase. Similar conclusions with respect to the subcellular localization of NADPH dehydrogenase were reached by Cartledge \& Lloyd (1972).

As compared to current procedures for the isolation of mitochondria from yeasts grown in batch or continuous culture, under our experimental conditions relatively high concentrations $(2 \mathrm{M})$ sorbitol were required to prevent premature lysis of spheroplasts. It is unlikely that this is solely caused by chemostat cultivation. $C$. utilis grown in batch culture on the same medium 
required $3 \mathrm{M}$-sorbitol for spheroplast stabilization (see also Zwart et al., 1983). In order to obtain functionally intact mitochondria, it is essential to establish the proper osmolarity of the incubation mixture for the stabilization of spheroplasts. Neglecting to optimize this parameter may lead to erroneous results as a consequence of premature lysis and liberation of digestive enzymes. Despite the virtually complete conversion of cells into spheroplasts, usually only $10 \%$ or at most $20 \%$ of the cell protein was collected in the crude homogenate fraction $\mathrm{T}$ (results not shown). Although in some isolation procedures a considerable amount of protein was lost as a result of centrifugation and washing, this low protein yield primarily results from the incomplete disruption of the spheroplasts. The yield of protein could only be increased at the expense of the quality of the mitochondria, as expressed in lower respiratory control values and a high degree of solubilization of NADH dehydrogenase, indicating that mitochondria were damaged.

Our objective was to develop an isolation procedure for mitochondria that is applicable to cells grown under various conditions in continuous culture. As this paper demonstrates for one yeast, the isolation procedure must be adapted to the growth conditions. When other yeasts are considered it is probable that additional adjustments in the isolation procedure will be required. In our opinion, one of the criteria to judge the success of these isolation procedures should be the distribution of NADH dehydrogenase among the isolated fractions.

Dr K. B. Zwart is thanked for personal communications.

We are indebted to Unilever Research Vlaardingen for a gift of Zymolyase-60000. Electron microscopy was performed by Mrs W. H. Batenburg-van der Vegte.

\section{REFERENCES}

Aiking, H., Sterkenburg, A. \& Tempest, D. W. (1977). Influence of specific growth limitation and dilution rate on the phosphorylation efficiency and cytochrome content of mitochondria of Candida utilis NCYC 321. Archives of Microbiology 113, 6572.

Bruinenberg, P. M., van Dijken, J. P. \& Scheffers, W. A. $(1983 a)$. A theoretical analysis of NADPH production and consumption in yeasts. Journal of General Microbiology 129, 953-964.

Bruinenberg, P. M., van DiJken, J. P. \& Scheffers, W. A. $(1983 b)$. An enzymic analysis of NADPH production and consumption in Candida utilis. Journal of General Microbiology 129, 965-971.

BruinenberG, P. M., van Dijken, J. P., Kuenen, J. G. \& SCHEFFERS, W. A. (1985). Oxidation of $\mathrm{NADH}$ and NADPH by mitochondria from the yeast Candida utilis. Journal of General Microbiology 131, 1043-1051.

Cartledge, T. G. \& Lloyd, D. (1972). Subcellular fractionation by differential and zonal centrifugation of aerobically grown glucose-derepressed $\mathrm{Sac}$ charomyces carlsbergensis. Biochemical Journal 126, 381-393.

Chance, B. \& Williams, G. R. (1956). The respiratory chain and oxidative phosphorylation. Advances in Enzymology 17, 65-134.

Delaissé, J. M., Martin, P., Verheyen-Bouvy, M. F. \& NYNS, E. J. (1981). Subcellular distribution of enzymes in the yeast Saccharomycopsis lipolytica, grown on n-hexadecane, with special reference to the $\omega$-hydroxylase. Biochimica et biophysica acta 676, 77 90.

Harder, W., Visser, K. \& Kuenen, J. G. (1974).
Laboratory fermenter with an improved magnetic drive. Laboratory Practice 23, 644-645.

HORECKER, B. L. (1978). Yeast enzymology : retrospectives and perspectives. In Biochemistry and Genetics of Yeasts. Pure and Applied Aspects, pp. 1-15. Edited by M. Bacila, B. L. Horecker \& A. O. M. Stoppani. New York, San Francisco, London: Academic Press.

Kärenlampi, S. O., Marin, E. \& Hänninen, O. O. P. (1981). Effect of carbon source on the accumulation of cytochrome $P-450$ in the yeast Saccharomyces cerevisiae. Biochemical Journal 194, 407-413.

Light, P. A. \& Garland, P. B. (1971). A comparison of mitochondria from Torulopsis utilis grown in continuous culture with glycerol, iron, ammonium, magnesium or phosphate as the growth-limiting nutrient. Biochemical Journal 124, 123-134.

LLOYD, D. (1974). The Mitochondria of Microorganisms. London, New York, San Francisco: Academic Press.

Schwitzguébel, J. P. \& Palmer, J. M. (1982). Properties of mitochondria as a function of the growth stages of Neurospora crassa. Journal of Bacteriology 149, 612-619.

TrinN, M., KäpPEli, O. \& Fiechter, A. (1982). Occurrence of cytochrome $\mathrm{P} 450$ in continuous cultures of Saccharomyces cerevisiae. European Journal of Applied Microbiology and Biotechnology 15, 6468.

Zwart, K. B., Veenhuis, M., Plat, G. \& Harder, W. (1983). Characterization of glyoxysomes in yeast and their transformation into peroxisomes in response to changes in environmental conditions. Archives of Microbiology 136, 28-38. 